\title{
Awareness and Knowledge about Antibiotic Use and Resistance among Students of Northern Border University Saudi Arabia
}

Samreen Soomro*, Hanan Oqla Alshammari and Yaqin Abdullah Alabbas

Northen Boarder University, Rafha, Saudi Arabia

*Corresponding author: Soomro S, Faculty of Pharmacy, Northen Boarder University, Rafha, Saudi Arabia, Tel: +254(0)221-622-778; E-mail: soomro.samreen@gmail.com

Received date: September 28, 2017; Accepted date: October 17, 2017; Published date: October 25, 2017

Copyright: () 2017 Soomro S, et al. This is an open-access article distributed under the terms of the Creative Commons Attribution License, which permits unrestricted use, distribution, and reproduction in any medium, provided the original author and source are credited.

\section{Abstract}

Background: Irrational antibiotic use has led society to antibiotic resistance a serious health problem worldwide, which is now trying to be solved by many various approaches. In 2011, the World Health Day theme was "Combat drug resistance: no action today means no cure tomorrow".

Objective: Objective of this study aimed examine the level of knowledge about antibiotic treatment and awareness of antibiotic resistance among the students at Northern Border University.

Materials and methods: A prospective cross-sectional study design was used to carry out this study from October 2016 to February 2017. The study was conducted among the students in Northern Border University with 202 participants. Data was collected by online questionnaire in Arabic language specially designed for the research purpose. Statistical analysis was done by utilizing MS Excel program.

Results: The study was based on questioners filled by students of NBU. The results suggested that among total male $13.4 \%$ and $86.6 \%$ female candidates, majority were pharmacy students. Nearly $34 \%$ complete antibiotic course but $66 \%$ did not finish the course since they feel better. About $9 \%$ change the antibiotic if they did not feel better. While $69.3 \%$ reported keeping leftover antibiotics at home for future need. $70 \%$ visit hospital and for clinical indication about $42 \%$ of respondents had used antibiotics for sore throat, and $19 \%$ for fever, $17 \%$ for common cold. $60 \%$ of respondents they heard about the bacteria resistance and the random use of antibiotic is harmful on the body. While $40 \%$ don't know what is bacteria resistance? And for the reasons of bacteria resistance, $29 \%$ use antibiotics unnecessarily. And $28 \%$ do not complete course, $23 \%$ use over the counter antibiotics.

In addition, $21.3 \%$ of respondents believed that resistant bacteria can be eradicated by increasing antibiotic dose, while $79 \%$ don't believe. $92 \%$ of respondents maintain a specific concentration of antibiotics. Moreover, $11.2 \%$ were not agreed about antibiotics that it work against all infections, while $53 \%$ think it treat viral infections.

Conclusion: In conclusion, this study revealed a high percentage of inappropriate antibiotic knowledge and a high rate of self-medication with antibiotics among students at NBU. Education programs should be developed, targeting specific public groups identified in this study, with lower antibiotic knowledge and higher self-medication risk.

Keywords: Antibiotics; Demographic; Gender; Race; Education level; Rational

\section{Introduction}

Irrational antibiotic use has led society to antibiotic resistance a serious health problem worldwide, which is now trying to be solved by many various approaches. In 2011, the World Health Day theme was "Combat drug resistance: no action today means no cure tomorrow" and for this occasion the World Health Organization introduced a sixpoint policy package to fight against the spread of anti-microbial resistance [1]. This reflects the importance of the problem and the need to undertake some serious actions in all population groups, involved in the growth of antimicrobial resistance and irrational antibiotic use.

There are various factors which may influence an increase in irrational antibiotic use. Many studies have reported that antibiotic regime non-adherence and in-appropriate antibiotic use are strongly associated with public awareness and knowledge of antibiotics [2-5]. Factors associated with public knowledge of antibiotics have been reported to be demographic characteristics, including gender [2,4,6-8], age $[6,8-12]$, race $[7,9]$, education level $[3,4,6-10,12-15]$, family income $[4,8,14]$, place of residence $[13,14]$, as well as other factors, such as lack of advice regarding rational antibiotic use, given by a physician [16]. Also, unregulated drug availability, inadequate antimicrobial drug quality assurance, inadequate surveillance and widespread attitude to antimicrobial misuse, include self-medication [17].

Another important issue related to the increase in antibiotic resistance is self-medication, which is defined as the acquisition of antibiotics and self-administering them (or administering them to children) with the aim of treating perceived infection [18]. There are clear differences between the prevalence rates of self-medication with 
Citation: Soomro S, Alshammari HO, Alabbas YA (2017) Awareness and Knowledge about Antibiotic Use and Resistance among Students of Northern Border University Saudi Arabia. J Trop Dis 5: 247. doi:10.4172/2329-891X.1000247

Page 2 of 4

antibiotics among different European countries, ranging from $5 \%$ to $45 \%[3,11,19,20]$ in the general population.

Irrational antibiotic use reflects not only patients' failure to comply with physician's instructions on how to use antibiotics adequately, but is also associated with inappropriate antibiotic prescribing. Rational antibiotic therapy should be based on the correct indication, the right drug and dosage, the drug of the first choice, the appropriate period of use, and the lowest treatment costs [21]. All antibiotic prescription events that do not comply with these conditions should be considered as irrational prescribing.

It is estimated that approximately two-thirds of all oral antibiotics used worldwide are obtained without a prescription and are inappropriately used for diseases such as tuberculosis, malaria, pneumonia, and for mild childhood infections [22].

In less affluent countries, antibiotic consumption appears to be increasing steadily due to expanded population, rising incomes, and improved access to health care. In contrast with developed countries, where outpatient antimicrobials are largely restricted to prescriptiononly use, non-prescription access to antimicrobials is common in less affluent countries, resulting in uncontrolled use and self-medication [17,23-25].

\section{Materials and Methods}

\section{Research design and data collection}

A prospective cross-sectional study design was used to carry out this study months from October 2016 to February 2017, the study was conducted in Northern Border university (NBU). The data was collected by using a self-administered online questionnaire in Arabic language specially designed for the research purpose (attached in appendix).

\section{Statistical analysis}

All data were analyzed using MS Excel by means of descriptive statistics.

\section{Results}

The study was based on questioners filled by students of NBU and met the inclusion criteria, total participate were about 202, the results suggested that among total male $13.4 \%$ and $86.6 \%$ female the participate were from Pharmacy, Medical and IT department. Nearly $34 \%$ of respondents prescribed an antibiotic completed the course. However, $66 \%$ of respondents reported that they did not finish their last antibiotic course as prescribed because they felt better. $9 \%$ changed the antibiotic if did not make them feel better (Figures 1 and 2). While $69.3 \%$ reported keeping leftover antibiotics at home in case of future need, and $30.7 \%$ reported NO. $70 \%$ reported they go to the hospital to visit the doctor. $17 \%$ reported they go to the pharmacy and ask for the same antibiotic. $4 \%$ reported they increase the dose (Table 1) and show $37 \%$ of students use antibiotic without prescribing and the most prescribing and the most prominent reason for it was easy access (Figure 3).

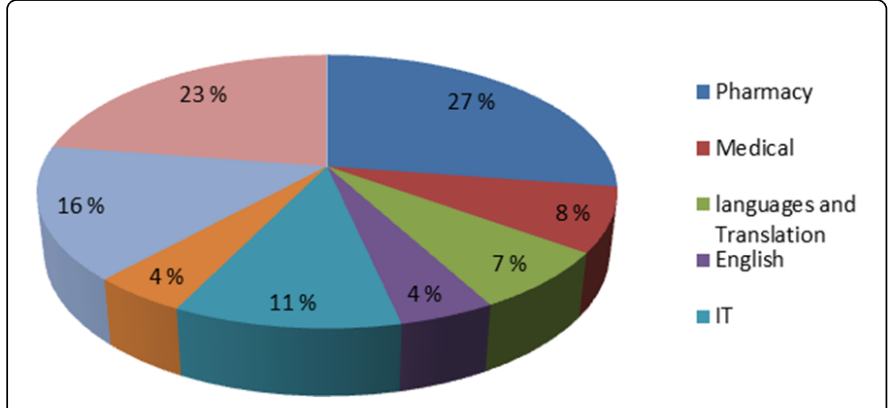

Figure 1: Fields of specializations of participants of the study.

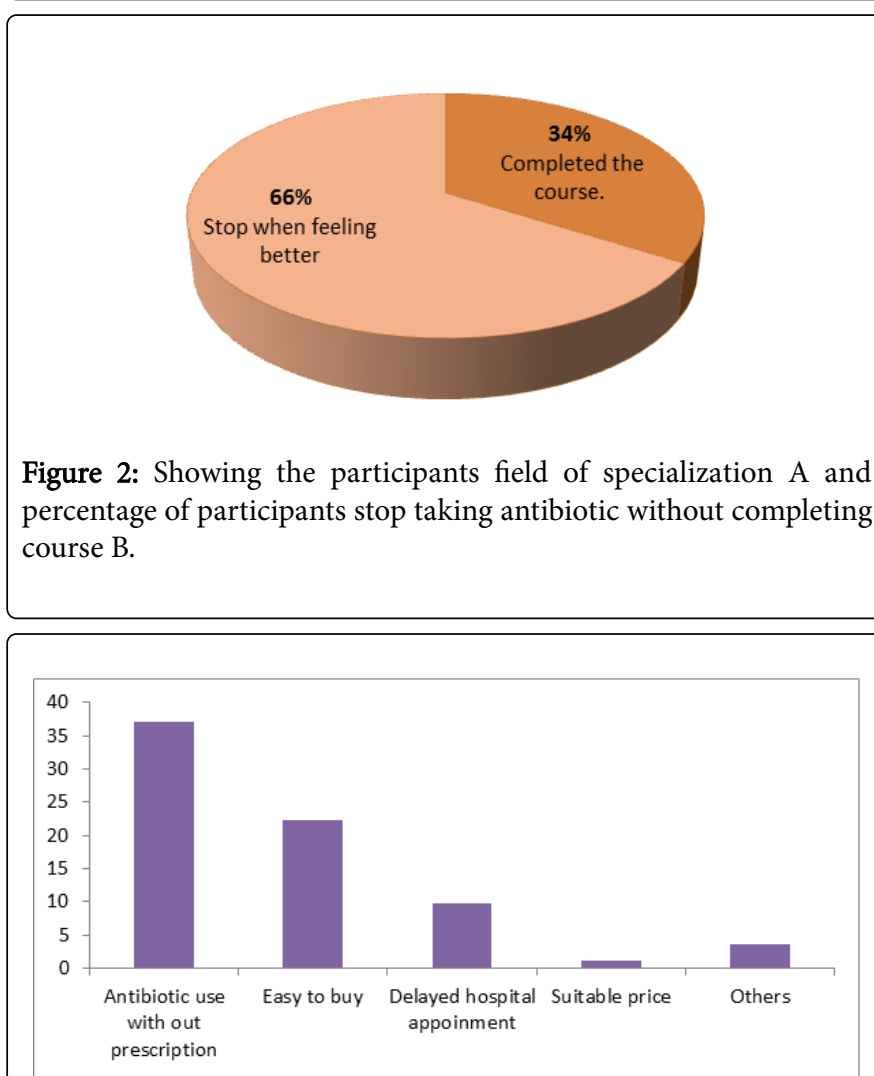

Figure 3: Represent the percentage of respondent use antibiotic without prescription.

\begin{tabular}{|l|l|}
\hline Statement & $\begin{array}{l}\text { No (\%) } \\
\text { (N=202) }\end{array}$ \\
\hline Go to the hospital to visit the doctor & $142(70.3)$ \\
\hline $\begin{array}{l}\text { Go to the pharmacy and ask for the same } \\
\text { antibiotic }\end{array}$ & $34(17)$ \\
\hline Increase the dose & $8(4)$ \\
\hline $\begin{array}{l}\text { Stop using the medicine and using another } \\
\text { medicine }\end{array}$ & $18(9)$ \\
\hline
\end{tabular}

Table 1: Self-reported principles of antibiotic use. 
Citation: Soomro S, Alshammari HO, Alabbas YA (2017) Awareness and Knowledge about Antibiotic Use and Resistance among Students of Northern Border University Saudi Arabia. J Trop Dis 5: 247. doi:10.4172/2329-891X.1000247

Page 3 of 4

For clinical indication about $42 \%$ of respondents had used antibiotics for sore throat, and $19 \%$ for fever, $17 \%$ for common cold, and $11 \%$ used it for toothache (Table 2). $60 \%$ of respondents they heard about the bacteria resistance and the random use of antibiotic is harmful on the body. While $40 \%$ don't know what is bacteria resistance? And for the reasons of bacteria resistance, $29 \%$ of respondents they think the use of antibiotics when is no necessity is the reason. And $28 \%$ do not complete a full cycle of antibiotics. $23 \%$ of respondents use of over-the-counter antibiotics, $13 \%$ of respondents take antibiotics with another medicine and $7 \%$ of respondents use the same antibiotics but trade names different (Table 3).

\begin{tabular}{|l|l|}
\hline $\begin{array}{l}\text { No. (\%) } \\
\mathbf{( N = 2 0 2 )}\end{array}$ & Reasons \\
\hline $84(42)$ & Sore throat \\
\hline $39(19)$ & Fever \\
\hline $35(17)$ & Common cold \\
\hline $23(11)$ & Toothache \\
\hline $8(4)$ & Headache \\
\hline $7(3.5)$ & Muscle soreness \\
\hline
\end{tabular}

Table 2: Indication for antibiotic use.

In addition, $21.3 \%$ of respondents believed that resistant bacteria can be eradicated by increasing antibiotic dose, while $79 \%$ of respondents don't believed of that $92 \%$ of respondents maintain a specific concentration of antibiotics, while $8 \%$ do not. And for the safe antibiotics during pregnancy $54 \%$ of respondents they think is various from type to another. $45 \%$ of respondents say isn't safe at all. $112 \%$ of respondents they don't agree about antibiotics work against all infections, While 54\% don't know, and 36\% say yes it can be. And 53\% of respondents they think antibiotic work against any infections caused by viruses, and $47 \%$ don't agree.

\begin{tabular}{|l|l|}
\hline Statements & $\begin{array}{l}\text { No (\%) } \\
(\mathbf{N}=202)\end{array}$ \\
\hline Use of antibiotics when there is no necessity & $59(29)$ \\
\hline Do not complete a full cycle of antibiotics & $56(28)$ \\
\hline Use of over the counter antibiotics & $47(23)$ \\
\hline Use the same antibiotics but trade names different & $13(7)$ \\
\hline Take antibiotics with another medicine & $27(13)$ \\
\hline
\end{tabular}

Table 3: Percentage of respondents agreeing and believing with statements regarding antibiotic resistance $(n=202)$.

Nearly half the participants prefer to keep antibiotic in home for future need. While Augmentin is one of the most widely administered antibiotic among Saudis (Figure 4).

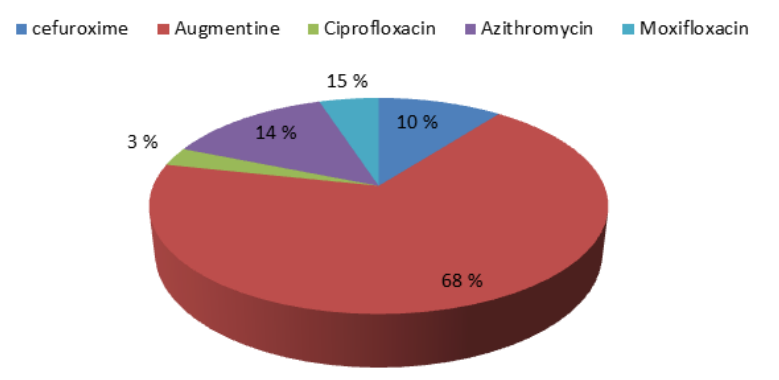

Figure 4: Most self-administered antibiotic use.

\section{Discussion}

Drug resistances among people of Saudi Arabia have been an important issue to be addressed drug resistance means misuse of antibiotic by the population without prescription. In this context we have we have designed a questioner regarding the miss use of antibiotic among students of NBU. We selected them just to ensure that level of education has no impact on raising drug resistance among people because of this misuse.

Our data suggested that there are high incidence rate of misused antibiotic among students at NBU is persistent because as show the percentage about $86.6 \%$ female and $13.4 \%$ male are mishandling the antibiotic. The most mishandling antibiotic was Augmentin with $68 \%$ and second Moxifloxacin 15\% and Azithromycin was 14\% and rest Cefuroxime and Ciprofloxacin.

Results also indicating that people try to use antibiotic themselves, representing their negligence respect to their own health. In some way some of them also used leftover drug, they may found it easy to buy $60.4 \%$ and second reason is delayed the hospital appointment $26.7 \%$ and suitable prices $3 \%$

The reasons for self-administration of non-prescribed antibiotics are varied. Although poor regulation of antimicrobials resulting from policies not being enforced is the major factor influencing selfmedication, it is not the only one accounting for this behavior [26,27].

In our study show their high percentage of respondents who known bacteria resistance about $60 \%$ and $40 \%$ don't know while they already don't complete the course.

Several studies already provided evidence of inappropriate antimicrobial use for the treatment of bacterial infections; this current study results are similar $[28,29]$. The most common reasons for antibiotic use were sore throat, fever and colds where the cause is likely to be viral. For a condition to be considered a minor ailment and selfmanaged depended not only upon the severity, but on previous experience and knowledge as well.

However, there was a very robust correlation between awareness of adverse reactions and antibiotic prescription. This correlation suggests that patient who is apprehensive about antibiotic side effects do not attempt to self-medicate and consulted their physician. A possible explanation is that those patients may have learned about the adverse impact of antibiotic use from their physician or pharmacist or from personal experience with antibiotic side effects. 
Strengths of this study in that it include high as well as low level of education among participants but also there's some limitations to the study. First, the sample was small thereby limiting the generalizability of the results. A second the results are based on self-reported behaviour, which may not represent actual behaviour. Third, the high female to male ratio found in this study is not a truly representative value for actual gender distribution in the population.

\section{Conclusion}

In conclusion, this study revealed a high percentage of inappropriate antibiotic knowledge and a high rate of self-medication with antibiotics among Students at NBU. Education programs should be developed, targeting specific public groups identified in this study, with lower antibiotic knowledge and higher self-medication risk. Finally, the attention of health care policy makers should be focused on physicians and pharmacists, as the main information providers of rational antibiotic use, as well as on community pharmacies, identified as the main source of nonprescription antibiotics.

\section{References}

1. World Health Organisation (2011) World Health Day 2011: Policy briefs WHO, Geneva.

2. Chan YH, Fan MM, Fok CM, Lok ZL, Ni M, et al. (2012) Antibiotics nonadherence and knowledge in a community with the world's leading prevalence of antibiotics resistance: Implications for public health intervention. Amer J Infect Control 40: 113-117.

3. McNulty CA, Boyle P, Nichols T, Clappison P, Davey P, et al. (2007) Don't wear me out. The public's knowledge of and attitudes to antibiotic use. J Antimicrob Chemother 59: 727-738.

4. You JHS, Yau B, Choi KC, Chau CTS, Huang QR, et al. (2008) Public knowledge, attitudes and behavior on antibiotic use: A telephone survey in Hong Kong. Infection 36: 153-157.

5. Awad AI, Aboud EA (2015) Knowledge, Attitude and practice towards antibiotic use among the public in Kuwait 10: 11-91.

6. Hoffmann K, Ristl R, Heschl L, Stelzer D, Maier M, et al. (2014) Antibiotics and their effects: What do patients know and what is their source of information? Eur J Public Health 24: 502-507.

7. Lim KK, Teh CC (2012) A Cross sectional study of public knowledge and attitude towards antibiotics in Putrajaya, Malaysia. Med Rev 5: 26-33.

8. Barah F, Gonçalves V (2010) Antibiotic use and knowledge in the community in Kalamoon, Syrian Arab Republic: A cross-sectional study. East Mediterr Health J 16: 516-521.

9. Ling OA, Hassali MA, Al-Haddad MS, Syed SA, Shafie AA, et al. (2011) Public knowledge and attitudes towards antibiotic usage: A crosssectional study among the general public in the state of Penang, Malaysia. J Infect Dev Ctries 5: 338-347.

10. Jose J, Jimmy B, Alsabahi AGMS, AlSabei GA (2013) A study assessing public knowledge, belief and behavior of antibiotic use in an omani population. Oman Med J 28: 324-330.

11. Napolitano F, Izzo MT, Giuseppe G, Angelillo IF (2013) Public knowledge, attitudes, and experience regarding the use of antibiotics in Italy.
12. Kim SS, Moon S, Kim EJ (2011) Public knowledge and attitudes regarding antibiotic use in South Korea. J Korean Acad Nurs 41: 742-749.

13. Godycki CM, Cals JWL, Francis N, Verheij T, Butler CC, et al. (2014) Public beliefs on antibiotics and symptoms of respiratory tract infections among rural and urban population in Poland: A questionnaire study. PLoS ONE 9: 13-71.

14. Mouhieddine TH, Olleik Z, Itani MM, Kawtharani S, Nassar H, et al. (2015) Assessing the Lebanese population for their knowledge, attitudes and practices of antibiotic usage. J Infect Public Health 8: 20-31.

15. Alzoubi K, Al-Azzam S, Alhusban A, Mukattash T, Al-Zubaidy SY, et al. (2013) An audit on the knowledge, beliefs and attitudes about the uses and side-effects of antibiotics among outpatients attending 2 teaching hospitals in Jordan. East Mediterr Health 19: 478-484.

16. Fernandes M, Leite A, Basto M, Nobre MA, Vieira N, et al. (2014) Nonadherence to antibiotic therapy in patients visiting community pharmacies. Int J Clin Pharm 36: 86-91.

17. Okeke IN, Laxminarayan R, Bhutta ZA, Duse AG, Jenkins P, et al. (2005) Antimicrobial resistance in developing countries. Part I: recent trends and current status. Lancet Infect Dis 5: 481-493.

18. Awad A, Eltayeb I, Matowe L, Thalib L (2005) Self-medication with antibiotics and antimalarials in the community of Khartoum State, Sudan. J Pharm Pharm Sci 8: 326-331.

19. Ivanovska V, Zdravkovska M, Bosevska G, Angelovska B (2013) Antibiotics for upper respiratory infections: Public knowledge, beliefs and self-medication in the Republic of Macedonia. Prilozi 34: 59-70.

20. Berzanskyte A, Valinteliene R, Haaijer FM, Gurevicius R, Grigoryan L, et al. (2006) Self-medication with antibiotics in Lithuania. Int J Occup Med Environ Health 19: 246-253.

21. World Health Organisation (2011) The World Medicines Situation 2011. WHO, Geneva.

22. Gannon J (2000) The global infectious disease threat and its implications for the United States. National Intelligence Council, Washington. p. 52.

23. Okeke IN, Klugman KP, Bhutta ZA, Duse AG, Jenkins P, et al. (2005) Antimicrobial resistance in developing countries. Part II: strategies for containment. Lancet Infect Dis 5: 568-580.

24. Okeke IN, Lamikanra A, Edelman R (1999) Socio-economic and behavioral factors leading to acquired bacterial resistance to antibiotics in developing countries. Emerg Infect Dis 5: 18-27.

25. Morgan DJ, Okeke IN, Laxminarayan R, Perencevich EN, Weisenberg S, et al. (2011) Non-prescription anti-microbial use worldwide: a systematic review. Lancet Infect Dis 11: 692-701.

26. Chalker J, Ratanawijitrasin S, Chuc NT, Petzold M, Tomson G, et al. (2005) Effectiveness of a multicomponent intervention on dispensing practices at private pharmacies in Vietnam and Thailand-a randomized controlled trial. Soc Sci Med 60: 131-141.

27. Wilson AA, Crane LA, Barrett PH, Gonzales R (1999) Public beliefs and use of antibiotics for acute respiratory illness. J Gen Intern Med 14: 658-662.

28. Raz R, Edelstein H, Grigoryan L, Haaijer-Ruskamp FM (2005) Selfmedication with antibiotics by a population in Northern Israel. Isr Med Assoc J 7: 722-725.

29. Cantrill J, Morris C, Weiss MC (2006) How patients perceive minor illness and factors influencing seeing a doctor. Prim Health Care Res Dev 7: $157-164$. 